\title{
Ultrasonography and CT Guided Percutaneous Renal Biopsy in Diagnosis of Renal Parenchymal Diseases
}

\author{
Atef Hammad Teama ${ }^{1}$, Kamal Mohamed Okasha ${ }^{2}$, Sameh Ahmed Khodair ${ }^{1}$, \\ Rehab Mohamed EL-Nagar ${ }^{1}$ \\ ${ }^{1}$ Radiodiagnosis \& Medical Imaging Department, Faculty of Medicine, Tanta University, Tanta, Egypt \\ ${ }^{2}$ Internal Medicine, Faculty of Medicine, Tanta University, Tanta, Egypt
}

\section{Email address:}

atef.teama@yahoo.com (A. H. Teama), okasha70@yahoo.com (K. M. Okasha), samehkhodair@gmail.com (S. A. Khodair), dr.rehabelnagar@yahoo.com (R. M. EL-Nagar)

\section{To cite this article:}

Atef Hammad Teama, Kamal Mohamed Okasha, Sameh Ahmed Khodair, Rehab Mohamed EL-Nagar. Ultrasonography and CT Guided Percutaneous Renal Biopsy in Diagnosis of Renal Parenchymal Diseases. International Journal of Medical Imaging.

Vol. 3, No. 6, 2015, pp. 114-129. doi: 10.11648/j.ijmi.20150306.13

\begin{abstract}
Objective: to evaluate the role of US \&CT guided percutanous renal biopsy (PRB) in diagnosis and monitoring of renal parenchymal diseases. Patients \&Methods: This study included 30 patients who were presented by and/or known cases of renal parenchymal disease referred for US and/or CT guided PRB for etiological \& histopathological diagnosis. The histopathological results were correlated with clinical, US \& laboratory data for each patient. Results: Out of those 30 patients; 29 patients had adequate PRB (29/30) (96.7\%) for histopatholgical diagnosis. Out of those 29 patients; 23 showed increase in renal cortical echogenicity (13 with GI, 8 with GII, \&2 with GIII) \& 6 cases showed normal echogenicity (G0). The lupus nephritis was the most accounted diagnosis (16/29) (55.2\%)(7 with GI, 5 with GII, 4 with G0 cortical echogenicity). The glomerular changes were depicted in 25 cases ( 13 with GI, 7 with GII, 2 with GIII, 3 with G0), tubular changes in 21 cases (10 with GI, 7 with GII, 2 with GI, 2 with G0), and interstitial changes in 24 cases (12 with GI, 8 with GII, 2 with GIII, 2 with G0). Post biopsy complications (minor) were accounted only in 2 cases (2/30) (6.7\%). Conclusions: Ultrasound PRB is the standard method for most non-focal renal biopsies as it has the advantage of real-time needle placement without radiation \& fundamental procedure for diagnosis, monitoring \&treatment of RPD. US and CT guided PRB is generally considered safe with minimal risk.
\end{abstract}

Keywords: Ultrasound Guided, Renal Biopsy, CT Guided, Renal Parenchymal Disease

\section{Introduction}

The prevalence of chronic kidney disease (CKD) is so high that is simulates a worldwide epidemic and public health problem all over the world. In UK, the prevalence of CKD stage 3-5 (GFR $<60 \mathrm{~mL} / \mathrm{min} / 1.73 \mathrm{~m} 2)$ is estimated to be $8.5 \%$. [1] In United States, the prevalence of CKD based on data from the NHANES III was $11 \%$ (3.3\% with stage $1,3 \%$ with stage $2,4.3 \%$ with stage $3,0.2 \%$ with stage 4 , and $0.2 \%$ with stage 5) [2]. Barsoum declared in a statistic done at 2003 based on the available data in the period between 19932002 that the incidence of end stage renal disease (ESRD) in Egypt 74 per million population [3].

In renal pathologies, diagnosis is based on the patient's clinical history, outcome of physical examination, laboratory tests, scintigraphy, diagnostic imaging and renal biopsy.
Particularly diagnostic imaging is an important tool as it is essential to exclude urinary tract obstruction, differentiate between acute and chronic pathologies, follow-up on diagnosed diseases and guide biopsy. US and color Doppler US are used in the initial evaluation as both are widely available, easy to perform, inexpensive and have no undesired side effects. [4]

Years ago, chronic GN (glomerulonephritis IgA being the most common form) was the most common cause of ESRD in adults. US findings are nonspecific and renal biopsy is required for diagnosis. In the incipient stage of the CRD, the kidney can appear normal on US, but in later stages it is characterized by a reduction in renal size, thinning and irregularity of the parenchyma, which appears hyperechoic reflecting fibrosis and sclerosis), sometimes containing simple cysts. Occasionally, renal biopsy is performed even 
in later stages, not to modify therapy but to assess primary renal disease and its possible recurrence after transplantation. [5]

Percutaneous renal biopsy (PRB) is a safe and effective tool in the diagnosis and management of renal disease. It is the gold standard for evaluating RPD. It is both useful for diagnosis and monitoring progress of renal diseases. The success of the procedure is defined not only by the ability to obtain adequate tissue for diagnosis but equally, if not more importantly, by the safety profile. Overall, the PRB has become a relatively safe procedure, with life-threatening complications occurring in $0.1 \%$ of biopsies in recent reports. [6]

The renal biopsy is an essential tool in the diagnosis and management of renal disease in native and transplanted kidneys. It allows clinicians to establish a histological diagnosis and give the most accurate prognosis. It may reveal a clinically unsuspected diagnosis and allows clinical presentations with many possible causes to be treated most appropriately. This is especially important in patients where multiple etiologies are being considered, such as a patient with diabetes mellitus who has nephrotic range proteinuria. In addition, it allows us to make predictions regarding patient and renal outcome by correlating pathological entities with established clinical outcome and treatment data. Lastly, it allows the degree of acute (reversible) or chronic (irreversible) damage to be assessed, so that clinicians can balance the risks and benefits of treatment, based on the likelihood of success or failure [7].

Current biopsy techniques involve CT or US guidance with small gauge needles. US has the advantages of real-time needle placement and no radiation and is therefore well suited for most non focal renal biopsies. CT has the advantage of better resolution and tissue contrast [8].

With the help of light and electron microscopy and immuno-fluorescent examination of renal tissues, the renal pathologist has been able to classify glomerulonephritis, to describe their clinico-pathological correlation, natural history and to study their pathogenesis. The clinicians utilize the information for the diagnosis and monitoring of treatment of their patients [9].

\subsection{Patients \& Methods}

This study included 30 patients who were presented with and/or known cases of RPD, referred from the Nephrology Units of Internal Medicine and Pediatric Departments to Radio-diagnosis and Medical Imaging Department, for US and/or CT guided PRB of native kidney for etiological \& histopathological diagnosis. This study was performed at the period from May 2012 to March 2013.

This study was approved by local research \& ethical Committee. The aim, method, limitation \& risk of technique were described to every patient before doing examination. No cost concerning the radiological procedures was afforded up on any patient. An informed consent was obtained before the start of the procedure.

Inclusion criteria; This study included patients with one or more of these findings; significant proteinuria ( $>1 \mathrm{gm} /$ day $)$, microscopic hematuria, unexplained renal impairment, and renal manifestations of systemic disease.

Exclusion criteria; This study excluded patients with one or more of these finding; uncontrolled bleeding diathesis, uncontrolled hypertension and Uncooperative patient, also the patients with obstructive uropathy were excluded from this study.

Every patient was subjected to the following:

\subsection{Thorough History Taking}

With special stress on presenting complaint like anuria, dysuria, discolored urine \& urine retention, peri-orbital, generalized edema, previous history of impaired renal function, SLE, hypertension \& proteinuria.

\subsection{Complete Clinical Examination}

i. General examination: Blood pressure, pulse, temperature \&respiration.

ii. Local examinations for chest, cardiac, abdominal and for edema \& SLE manifestations.

\subsection{Laboratory Investigations}

- Complete urine analysis, serum creatinine, blood urea, serum C-reactive protein (CRP), lipid profile, liver function tests.

- Complete blood picture (packed cell volume, platelet count).

- Coagulation profile \{prothrombin time, international normalized ratio (INR), activated partial thromboplastin time and bleeding time\} were obtained before renal biopsy.

- Accepted coagulation parameters were; INR $\leq 1.5 \&$ platelets levels $\geq 50,000 /$ microliter (mcl).

\subsection{Abdominal Ultrasonography}

- All patients were examined at Ultrasound units of Radiology Department, two ultrasound machines (Siemens Sonoline G 60S, Biomedical P-K,) with 3.5 \& $5 \mathrm{MHZ}$ convex probe were used.

- Pre-biopsy US was performed to: ensure presence and position of both kidneys and absence of congenital abnormalities, define renal size and renal echogenicity\& reveal hydronephrosis, cysts, stones, or masses.

- Post-biopsy US was used to assess possible complications like peri-renal hematoma

\subsection{Biopsy Procedure}

i-Biopsy needles:

- Automated biopsy needles (18G x $20 \mathrm{~cm}$ or $16 \mathrm{G}$ x 20 $\mathrm{cm}$ ) with sampling length $22 \mathrm{~mm}$ loaded on a biopsy gun.

- The $18 \mathrm{G}$ needle was used in patients $\leq 16$ years $(10$ patients) while the $16 \mathrm{G}$ needle was used in patients $>$ 
16 years (20 patients) to ensure the adequacy of the biopsy sample because that the internal diameter of the $18 \mathrm{G}$ needle $(300-400 \mu \mathrm{m})$ is only barely larger than the adult glomeruli $(200-250 \mu \mathrm{m})$.

ii-Patient Position:

Patients were placed in prone position

iii- Patient Preparation:

- Salycilic acid or non-steroidal anti-inflammatory drugs were stopped for at least 5 to 7 days before the biopsy procedure and the patient should remain off of such drugs for at least 1 week after the biopsy.

- Heparin should be stopped the day before the procedure.

- Vital signs were monitored. Blood pressure was corrected to be lower than 140/90 in patients with hypertension. Also coagulation parameters were corrected if not accepted (INR should be $\leq 1.5 \&$ platelets level $\geq 50,000 / \mathrm{mcl})$.

- Diet: Nil by mouth 4-6 h prior to the procedure.

- Children younger than 10 years old, IV midazolam $0.01 \mathrm{mg} / \mathrm{kg}$ was administered.

iv-Biopsy technique,

* Ultrasound guided PRB technique:

- The lower pole of the kidney and the entrance site was identified for biopsy.

- The skin was then prepped with $70 \%$ alcohol solution, followed by $2 \%$ lidocaine administration superficially at the skin biopsy site and along the intended biopsy tract.

- A small snip was then made to facilitate subsequent passage of the biopsy needle.

- The biopsy needle was then introduced under the guidance of real-time US with free-hand technique with the needle in plane with beam and the tip of the needle is followed in US field to reach the renal capsule.

- Firing of the biopsy gun was performed after indenting the renal capsule with the biopsy needle tip with patient breath hold \& firing distance $24 \mathrm{~mm}$.

- Two Cores were taken in all patients.

** CT guided PRB technique:

- CT guidance was used in only one case where the patient was obese and image quality by ultrasound was poor using single section helical CT at Radiology Department.

- Preliminary CT images at $5 \mathrm{~mm}$ axial slices covering the entire length of the kidney were obtained.

- The lower pole of kidney and the entrance site was identified for biopsy.

- The distance from the skin to the renal capsule was measured.

- The skin was then prepped with $70 \%$ alcohol solution, then local anathetic (2\% lidocaine) was administered superficially at the skin site and along the intended biopsy tract.

- A small snip was then made to facilitate subsequent passage of the biopsy needle.

- The biopsy needle was then introduced by a length equal to the distance from the skin to renal capsule

- The position of the needle tip was then confirmed by an additional CT scan.

- Firing of the biopsy gun was then performed while the patient was holding breath with firing distance $24 \mathrm{~mm}$.

- Two Cores were taken in all patients.

- The needle-cores of kidney tissue were embedded immediately in a formalin $10 \%$ solution.

\subsection{Post biopsy Monitoring}

-All patients were observed in the radiology department 1 hour after the procedure\& remained flat on the bed and closely monitored. At $1 \mathrm{~h}$ post-biopsy, the biopsied kidney was again examined by $\mathrm{U} / \mathrm{S}$.

Then, the patient was admitted to the hospital for $23 \mathrm{~h}$ of observation. In the medical ward, the patients continued to lie on the bed flat on their back for 4-6 h.

-Vital signs were checked every $15 \mathrm{~min}$ for $2 \mathrm{~h}$, every hour for $4 \mathrm{~h}$, every $2 \mathrm{~h}$ for $6 \mathrm{~h}$ and then every $4 \mathrm{~h}$ thereafter.

-Each urine void was checked for hematuria visually and the results were recorded.

-Patients were usually dismissed on morning after the biopsy if no complication was detected.

-All patients were given a telephone number to call if they believed they had problems related to the procedure.

-All patients undergoing renal biopsy were prospectively evaluated for the development of a post-biopsy complication. The severity of the complication was categorized as A) minor as those resulting in gross hematuria or peri-renal hematoma which spontaneously resolving without the need for further intervention or B) major as those resulting in the need for an intervention e.g. transfusion of blood products, an invasive procedure (radiological or surgical), or those resulting in acute renal obstruction, renal failure or septicemia.

-The histopathological results of PRB were recorded \& correlated with clinical \&lab. data for each patient.

\section{Results}

This study included 30 patients who presented clinically and/or known cases of renal parenchymal diseases \& referred from Nephrology Units of Internal Medicine \& Pediatric Department to Radiodiagnosis \& Medical Imaging Department for performing PRB of native kidney guided by US and/or CT for etiological \& histopathological diagnosis.

Those 30 patients of our study included 22 females \& 8 males, with age ranged from 2 to $64 \mathrm{ys}$ with mean age 23.7 years. Females were more affected $(22 / 30)(73.3 \%)$ in comparison to males $(8 / 30)(26.7 \%) \&$ the $2^{\text {nd }}$ decade age group were the most affected one (11/30)(36.7\%), followed by $3^{\text {rd }}$ decade group (10/30)(33.3\%).

Out of those 30 patients of our study; 11 patients were presented clinically by nephrotic syndrome (11/30), 5 patients with subnephrotic proteinuria $(5 / 30), 5$ patients with nephritic syndrome (acute glomerulonephritis) (5/30), 3 patients with hematuria\& proteinuria $(3 / 30)$

All 30 patients of our study underwent PRB by automatic 
biopsy needles $18 \mathrm{G} \times 20 \mathrm{~cm}$ used for younger patients ( $\leq$ $16 \mathrm{ys}) \& 16 \mathrm{G} \times 20 \mathrm{~cm}$ used for adult patients $(>16 \mathrm{Ys})$ to ensure the adequacy of the biopsy sample. The number of glomeruli obtained by the $18 \mathrm{G}$ needle ranged from 2-17 with average 7.45 glomeruli. The number of glomeruli obtained by the $16 \mathrm{G}$ needle ranged from 6-24 with average 13.2 glomeruli

We found that The biopsy sample was adequate in making definitive histopathological diagnosis in 29 patients $(29 / 30)(96.7 \%) \&$ inadequate in only one case (1/30)(3.3\%) because only two glomeruli were obtained in this case. The $18 \mathrm{Gx} 20 \mathrm{~cm}$ needle biopsy were more suitable for obtaining adequate biopsy sample in the younger patients $(\leq 16 \mathrm{ys}) \&$ unsuitable for adult patients ( $>16 \mathrm{ys}$ ) because of its internal diameter (300-400 Um) is only barely larger than the adult glomeruli (200-250 Um).

Those 29 patients with RPD \& who had adequate PRB were classified histopathologically (16 with LN, (16/29), 3 with IN (3/29), 2 with MsPGN (2/29). Table (1).

Tab. 1. Histopathological classification of 29 patients with RPD \& who had adequate PRB.

\begin{tabular}{lll}
\hline Histopathology & No. & \% \\
\hline Lupus nephritis (LN) & 16 & $55.2 \%$ \\
Interstitial nephritis(IN) & 3 & $10.3 \%$ \\
MsPGN & 2 & $6.9 \%$ \\
MCD & 1 & $3.4 \%$ \\
MPGN & 1 & $3.4 \%$ \\
MGN & 1 & $3.4 \%$ \\
IgA nephropathy & 1 & $3.4 \%$ \\
TMA & 1 & $3.4 \%$ \\
Amyloid & 1 & $3.4 \%$ \\
Cryoglobulinemic MPGN & 1 & $3.4 \%$ \\
ESRD & 1 & $3.4 \%$ \\
Inconclusive(non-adequate (biopsy). & 1 & $3.4 \%$ \\
Total No. & 30 & $100 \%$ \\
\hline
\end{tabular}

Out of 30 patients of our study who had performed PRB only two cases showed minor complications (2/30) (6.7) (one with peri-renal hematoma at $1 \mathrm{~h}$ post. biopsy\& one with hematuria $4 \mathrm{~h}$ post. biopsy, while the remained 28 patients hadn't complication either minor or major.

The pre-biopsy US findings \&the renal cortical echogenicity grading of each patient was recorded \& correlated with the RPD \& histopathological findings in 29 cases who had adequate PRB as shown in table (6), just 1 case $(1 / 30)$ was excluded because of suboptimal number of obtained glomeruli for definitive diagnosis.

Also renal cortical echogenicity were correlated with glomerular, tubular \& interstitial changes in each patient. There were six cases with grade 0 echogenicity, 13 cases with grade I echogenicity, 8 cases with grade II echogenicity and 2 cases with grade III echogenicity. The correlation of grading and microscopic findings are shown in tables (3), (4) \&Table (5).
Tab. 2. Correlation between renal cortical echogenicity and RPD \& histopathology in 29 patients with adequate PRP.

\begin{tabular}{llllll}
\hline RPD \& histopathology & \multicolumn{6}{l}{ Renal cortical echogenicity } & Total \\
\hline & G0 & GI & GII & GIII & \\
\hline LN & 4 & 7 & 5 & - & 16 \\
Interstitial nephritis & - & 2 & 1 & & 3 \\
MsPGN & 1 & - & 1 & & 2 \\
MCD & 1 & & & & 1 \\
MPGN & & 1 & & & 1 \\
MGN & & 1 & & & 1 \\
IgA nephropathy & & 1 & & & 1 \\
TMA & & & & 1 & 1 \\
Amyloid & & & 1 & & 1 \\
Cryoglobulinemic MPGN & & 1 & & & 1 \\
ESRD & & & & 1 & 1 \\
Total No. & 6 & 13 & 8 & 2 & 29 \\
\hline
\end{tabular}

G0: Normal (the cortical echogenicity of the right kidney was less than that of the liver).

GI: The cortical echogenicity of the right kidney equal to that of the liver

GII: The cortical echogenicity of the right kidney was greater than that of the liver but less than that of the renal sinus.

GIII: The cortical echogenicity of the right kidney was equal to that of the renal sinus.

Tab. 3. Correlation between glomerular changes and renal cortical echogenicity.

\begin{tabular}{|c|c|c|c|c|c|c|c|c|}
\hline \multirow[t]{2}{*}{ Glomerular changes } & \multicolumn{2}{|c|}{ G 0} & \multicolumn{2}{|c|}{ G I } & \multicolumn{2}{|c|}{ G II } & \multicolumn{2}{|c|}{ G III } \\
\hline & $\mathbf{N}$ & $\%$ & $\mathbf{N}$ & $\%$ & $\mathbf{N}$ & $\%$ & $\mathbf{N}$ & $\%$ \\
\hline $\begin{array}{l}\text { NAD (no golmerular } \\
\text { changes) }\end{array}$ & 3 & $50 \%$ & & & 1 & $12.5 \%$ & & \\
\hline $\begin{array}{l}\text { Mesangial } \\
\text { hypercellularity }\end{array}$ & 1 & $16.7 \%$ & 5 & $38.5 \%$ & 2 & $25 \%$ & & \\
\hline BM thickening & 1 & $16.7 \%$ & 1 & $7.7 \%$ & & & & \\
\hline $\begin{array}{l}\text { Endocapillary } \\
\text { proliferative changes }\end{array}$ & 1 & $16.7 \%$ & 3 & $23.1 \%$ & 1 & $12.5 \%$ & & \\
\hline $\begin{array}{l}\text { Mesang. } \\
\text { endocapillary } \\
\text { proliferative changes }\end{array}$ & & & 2 & $15.3 \%$ & 3 & $37.5 \%$ & & \\
\hline $\begin{array}{l}\text { Mesangial expansion } \\
\text { with BM thickening }\end{array}$ & & & & & & & 1 & $50 \%$ \\
\hline Sclerosis & & & 1 & $7.7 \%$ & 1 & $12.5 \%$ & 1 & $50 \%$ \\
\hline Obsolescence & & & 1 & $7.7 \%$ & & & & \\
\hline Total & 6 & $100 \%$ & 13 & $100 \%$ & 8 & $100 \%$ & 2 & $100 \%$ \\
\hline
\end{tabular}

Tab. 4. Correlation between renal tubular changes and cortical echogenicity.

\begin{tabular}{|c|c|c|c|c|c|c|c|c|}
\hline \multirow[t]{2}{*}{ Tubular changes } & \multicolumn{2}{|c|}{ G 0} & \multicolumn{2}{|c|}{ G I } & \multicolumn{2}{|c|}{ G II } & \multicolumn{2}{|c|}{ G III } \\
\hline & $\mathbf{N}$ & $\%$ & $\mathbf{N}$ & $\%$ & $\mathbf{N}$ & $\%$ & $\mathbf{N}$ & $\%$ \\
\hline $\begin{array}{l}\text { NAD(non-tubular } \\
\text { changes) }\end{array}$ & 4 & $66.6 \%$ & 3 & $23.1 \%$ & 1 & $12.5 \%$ & & \\
\hline \multicolumn{9}{|l|}{ Atrophy: Minor } \\
\hline Mild Moderate & 1 & $16.7 \%$ & & & & & & \\
\hline & 1 & $16.7 \%$ & 7 & $53.8 \%$ & 2 & $25 \%$ & & \\
\hline & & & 1 & $7.7 \%$ & 5 & $62.5 \%$ & & \\
\hline & & & & & & & 1 & $50 \%$ \\
\hline $\begin{array}{l}\text { Hydropic } \\
\text { degenertaion }\end{array}$ & & & 1 & $7.7 \%$ & & & & \\
\hline $\begin{array}{l}\text { Hyaline \&RBCs } \\
\text { cast }\end{array}$ & & & 1 & $7.7 \%$ & & & & \\
\hline Tubular necrosis & & & & & & & 1 & $50 \%$ \\
\hline Total & 6 & $100 \%$ & 13 & $100 \%$ & 8 & $100 \%$ & 2 & $100 \%$ \\
\hline
\end{tabular}


Tab. 5. Correlation between interstitial changes and cortical echogenicity.

\begin{tabular}{|c|c|c|c|c|c|c|c|c|}
\hline Interstitial changes & G 0 & & G I & & G II & & $\mathbf{G}$ & \\
\hline & $\mathbf{N}$ & $\%$ & $\mathbf{N}$ & $\%$ & $\mathbf{N}$ & $\%$ & $\mathbf{N}$ & $\%$ \\
\hline NAD (no interst. chang) & 4 & $66.6 \%$ & 1 & $7.7 \%$ & & & & \\
\hline Fibrosis & 1 & $16.7 \%$ & 1 & $7.7 \%$ & & & 1 & $50 \%$ \\
\hline Inflammation & & & 2 & $15.4 \%$ & 2 & $25 \%$ & & \\
\hline Edema & 1 & $16.7 \%$ & & & & & & \\
\hline Fibrosis \& inflammation & & & 9 & $69.2 \%$ & 6 & $75 \%$ & 1 & $50 \%$ \\
\hline Total & 6 & $100 \%$ & 13 & $100 \%$ & 8 & $100 \%$ & 2 & $100 \%$ \\
\hline
\end{tabular}
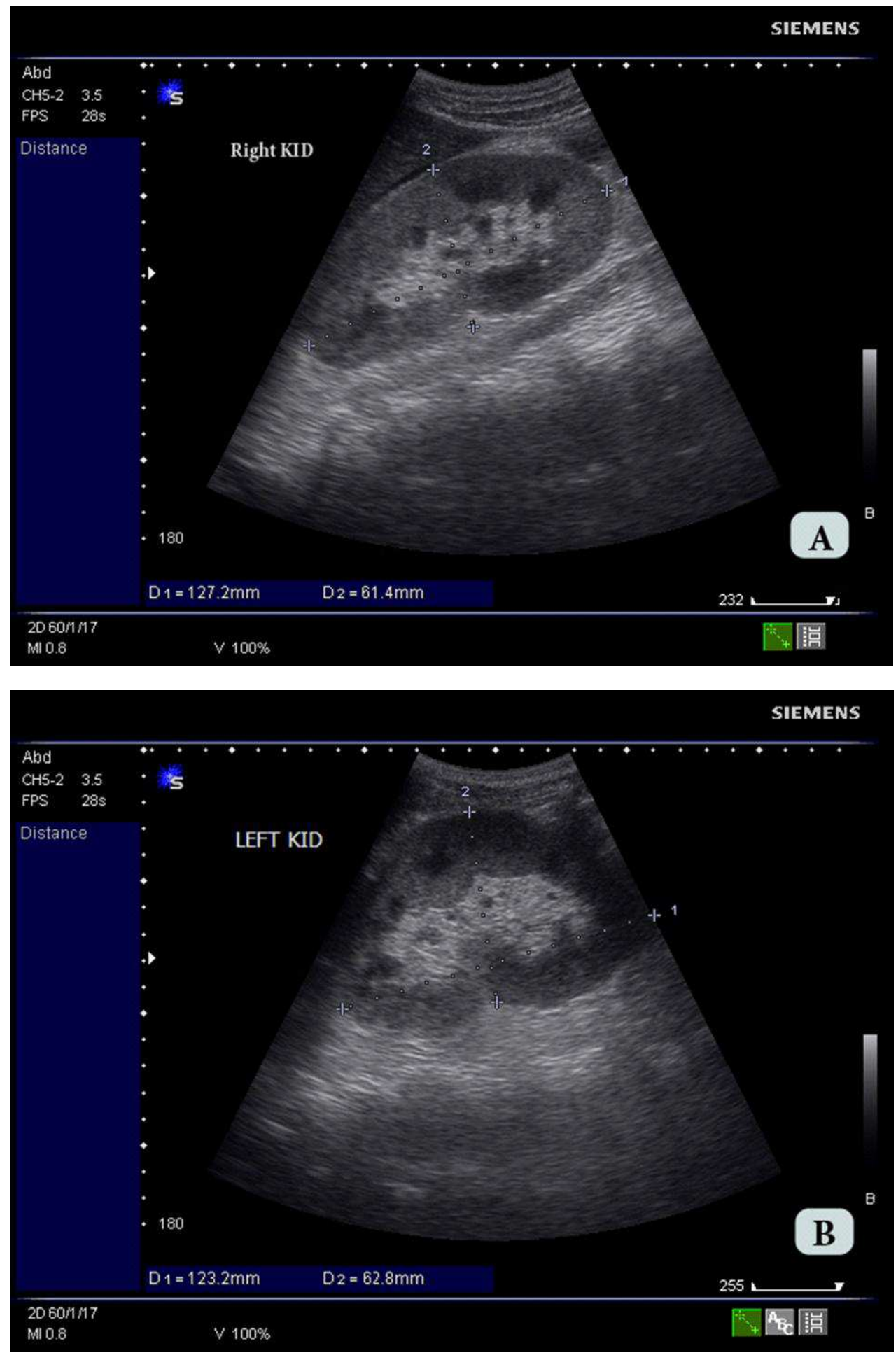

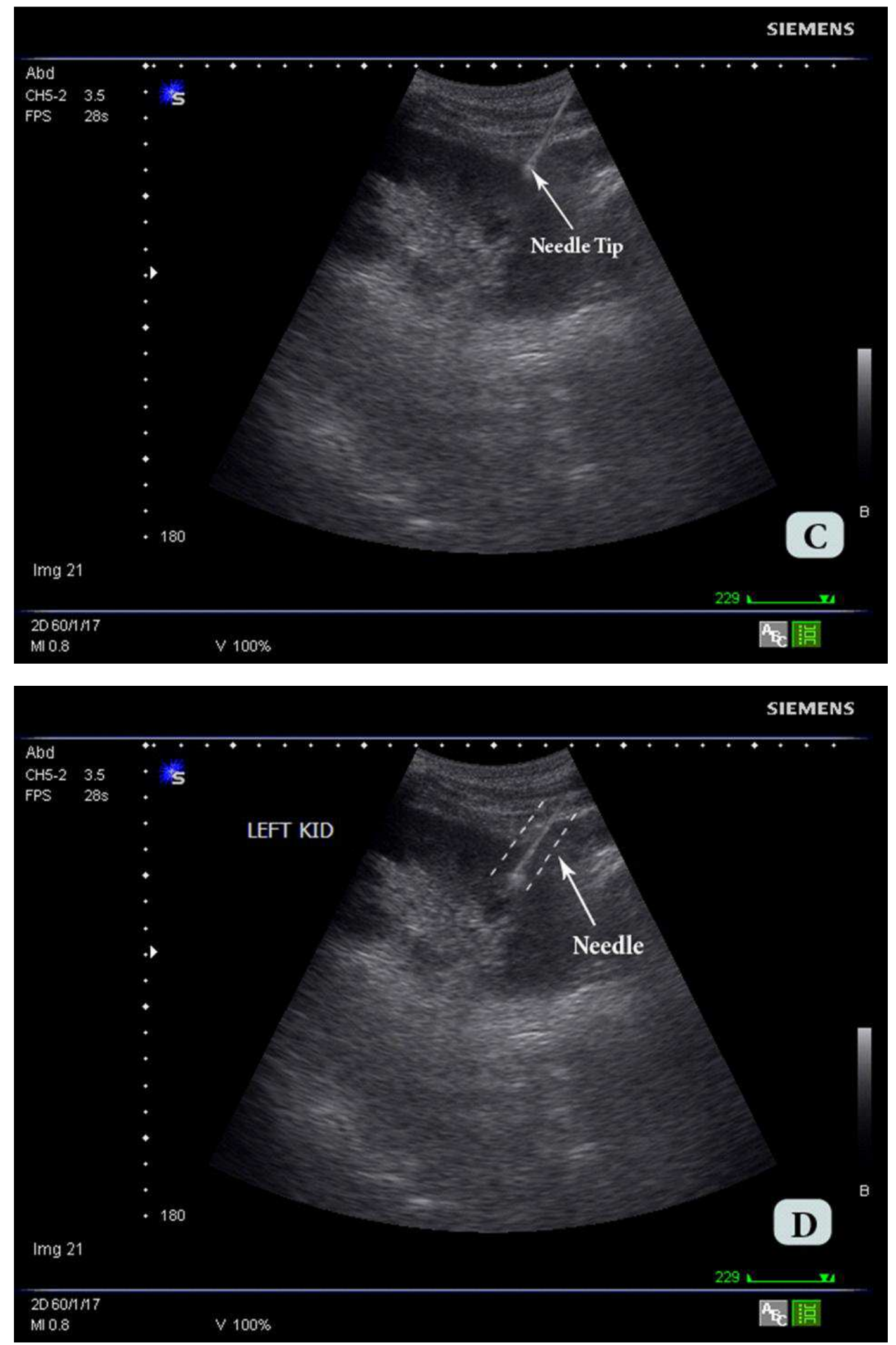

Fig. $1(\mathbf{l a}, \mathbf{1} \boldsymbol{b}, \mathbf{1} \boldsymbol{c}, \boldsymbol{\&} \mathbf{1 d})$. A male patient aged 33ys presented with unexplained renal impairment, hypertension \&hematuria. A) Real-time US, longitudinal section (LS) of the Rt. kidney revealed; normal sized kidney with average parenchymal thickness. (B) Real-time US (L.S.) of the Lt. kidney showed normal sized kidney with average parenchymal thickness. Both kidneys showed relative increase in their parenchymal reflectivity (GI). (C) U/S. (LS) of the Lt. kidney in prone position revealed the tip of biopsy needle (arrowed) at the renal capsule of the lower pole. (D) The needle path is outlined by two parallel dotted line, the needle itself seen as echogenic line.Two US guided core biopsies were taken \& revealed Membranoproliferative glomerulonephritis (MPGN). 

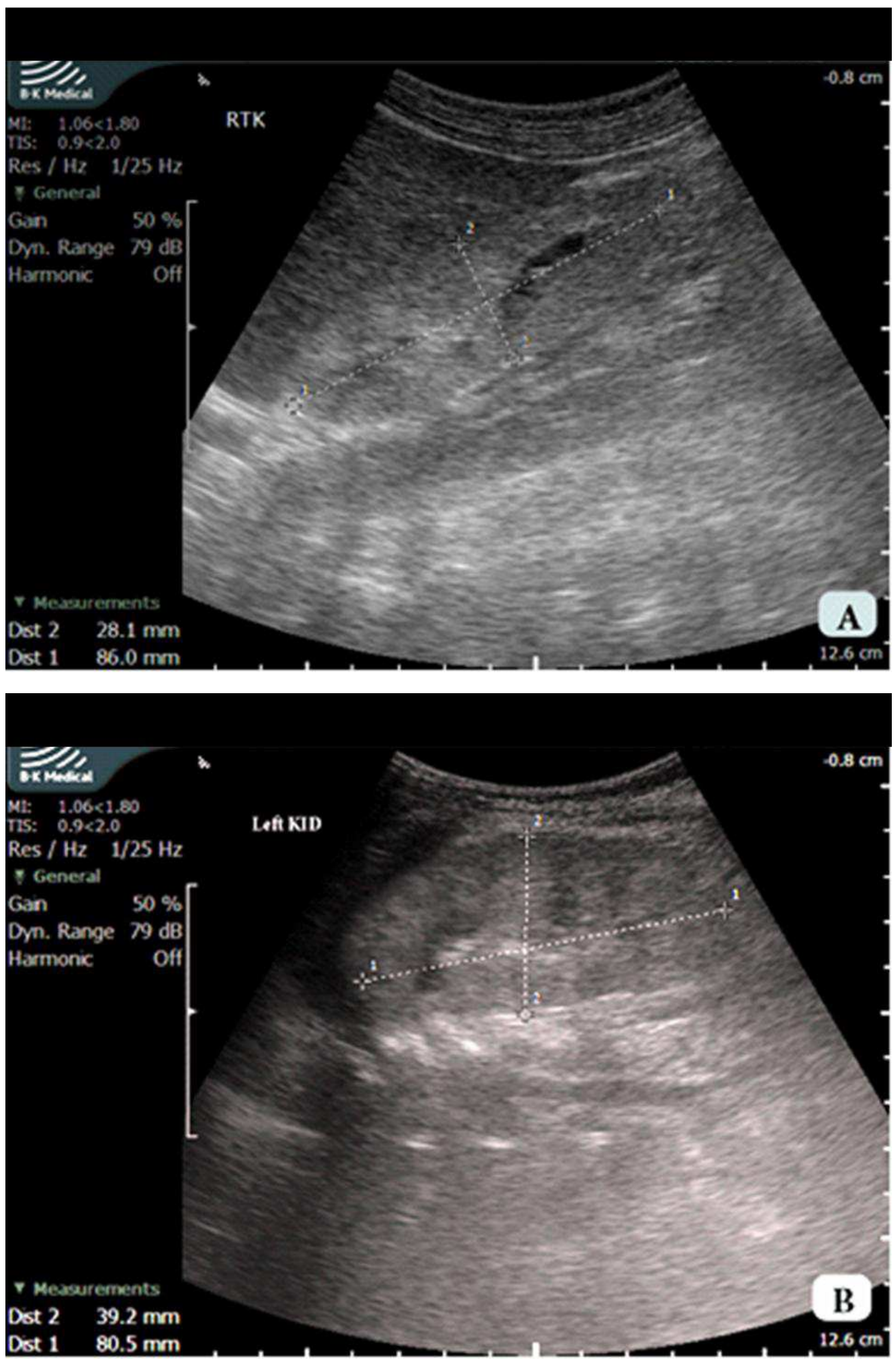

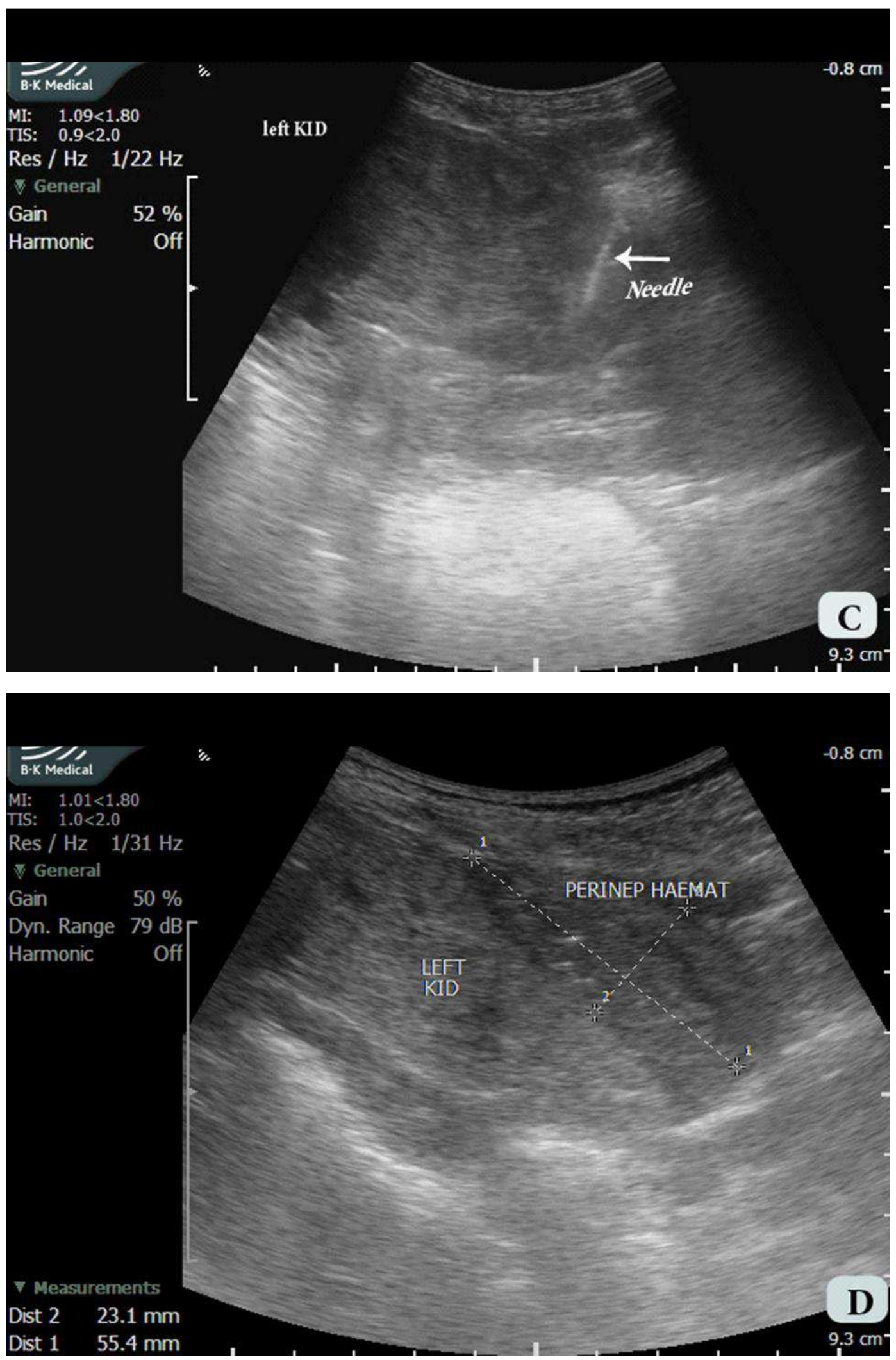

Fig. $2(2 a, 2 b, 2 c, \& 2 d)$. A female infant aged 2ys. Presented with acute rise of serum creatinine, hypertension, generalized edema, hematuria \& oliguria. (A) $\& B)$ Real time US) (LS.) of both kidneys revealed normal sized both kidneys with parenchymal thickness of about (16 mm) with increased their parenchymal reflectivity (GIII) \&loss of corticomedullary differentiation. (C) Real-time U/S guided biopsy showed biopsy needle in the lower pole of the Lt. kidney \& two core biopsies were taken \& revealed; Thrombotic microangiopathy (TMA) with regenerating acute tubular necrosis. In correlation with clinical \& lab. data; this case was diagnosed as hemolytic uremic syndrome (HUS). (D) $1 \mathrm{~h}$. Post.biopsy revealed peri-renal hematoma $(5.5 \times 2.3 \times 3 \mathrm{~cm})$. 

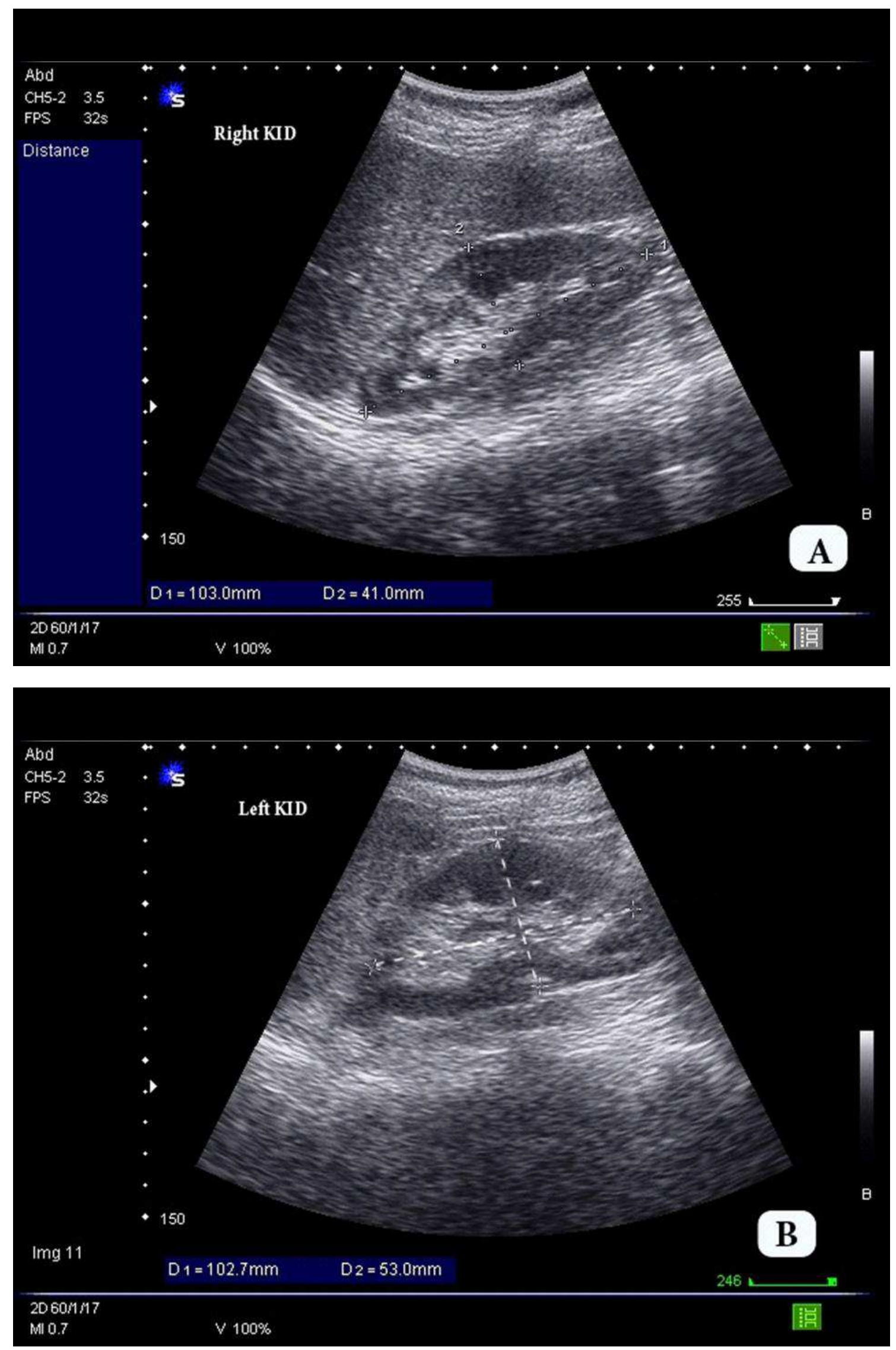


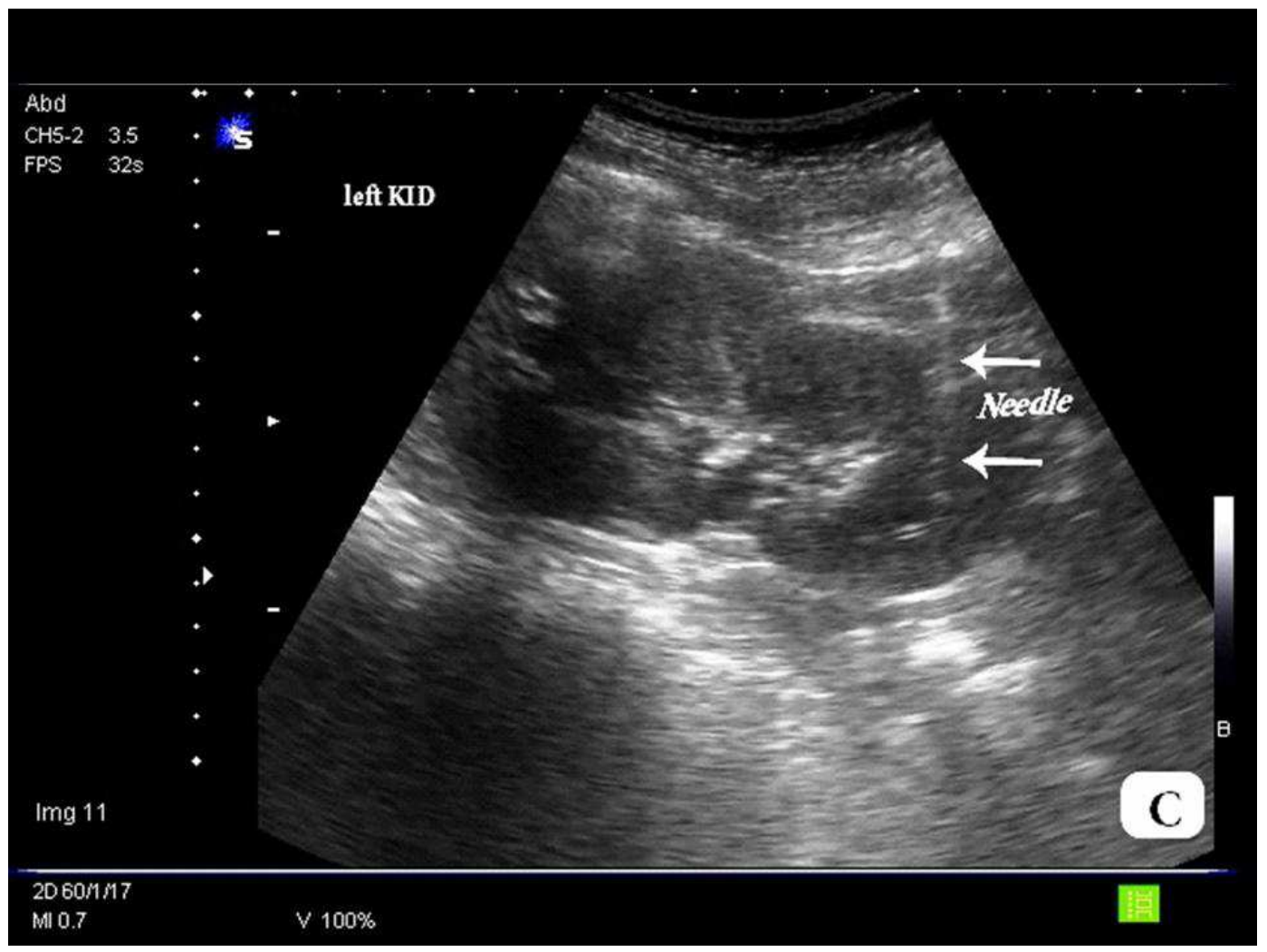

Fig. $3(3 a, 3 b, \& 3 c)$. A female patient aged 23ys.presented with nephrotic syndrome. (A) \& B) Real-time US (LS) of both kidneys revealed average sized either kidneys, with normal reniform shape \&average parenchymal thickness $(17.8 \mathrm{~mm})$ \& with normal parenchymal echotexture \& good corticomedullary differentiation. (C) US guided biopsy of the Lt. kidney in prone position showed the biopsy needle as an echogenic line (arrowed) in its lower pole .Two core biopsies were taken and revealed; minimal change disease (MCD).

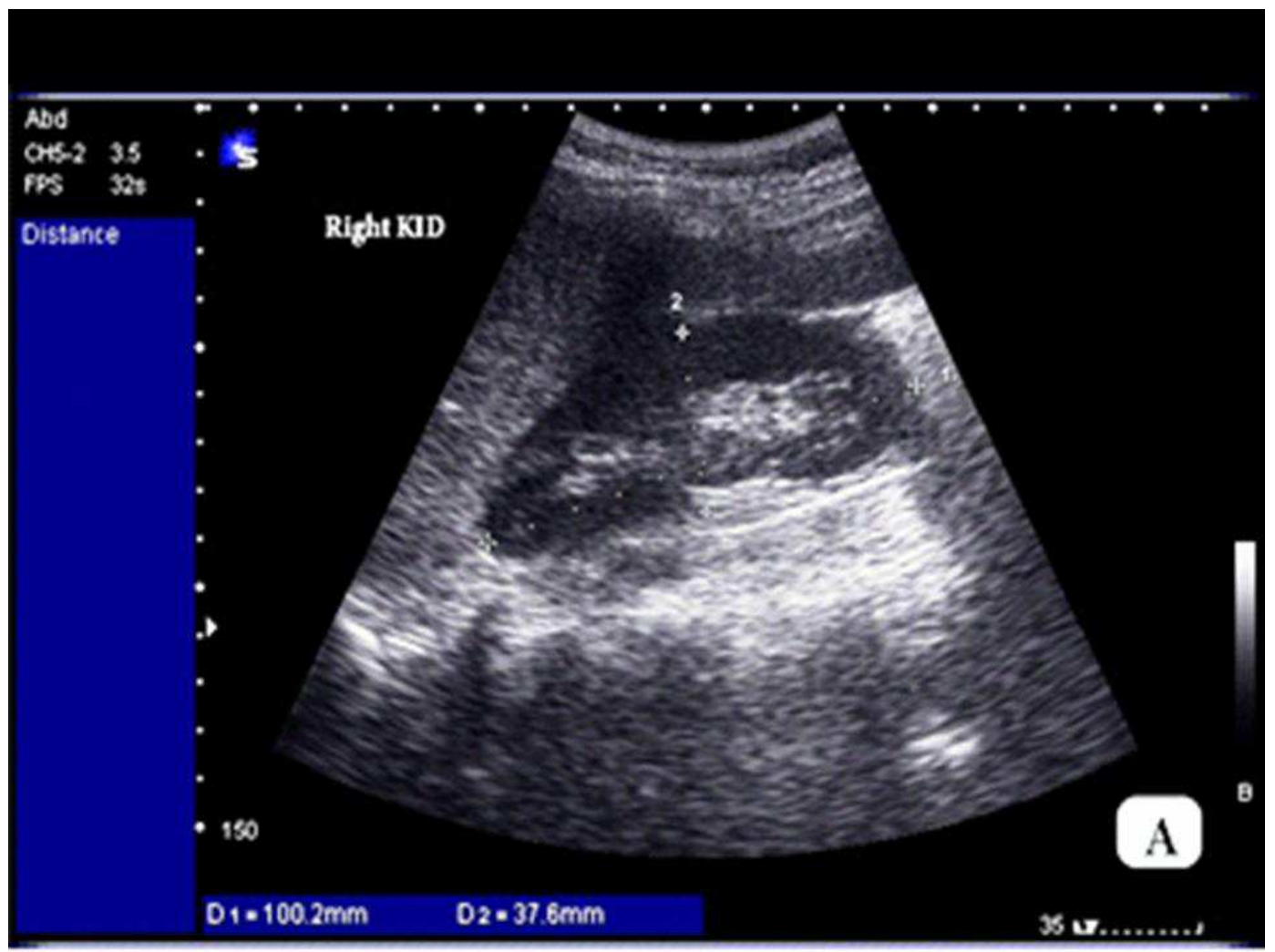



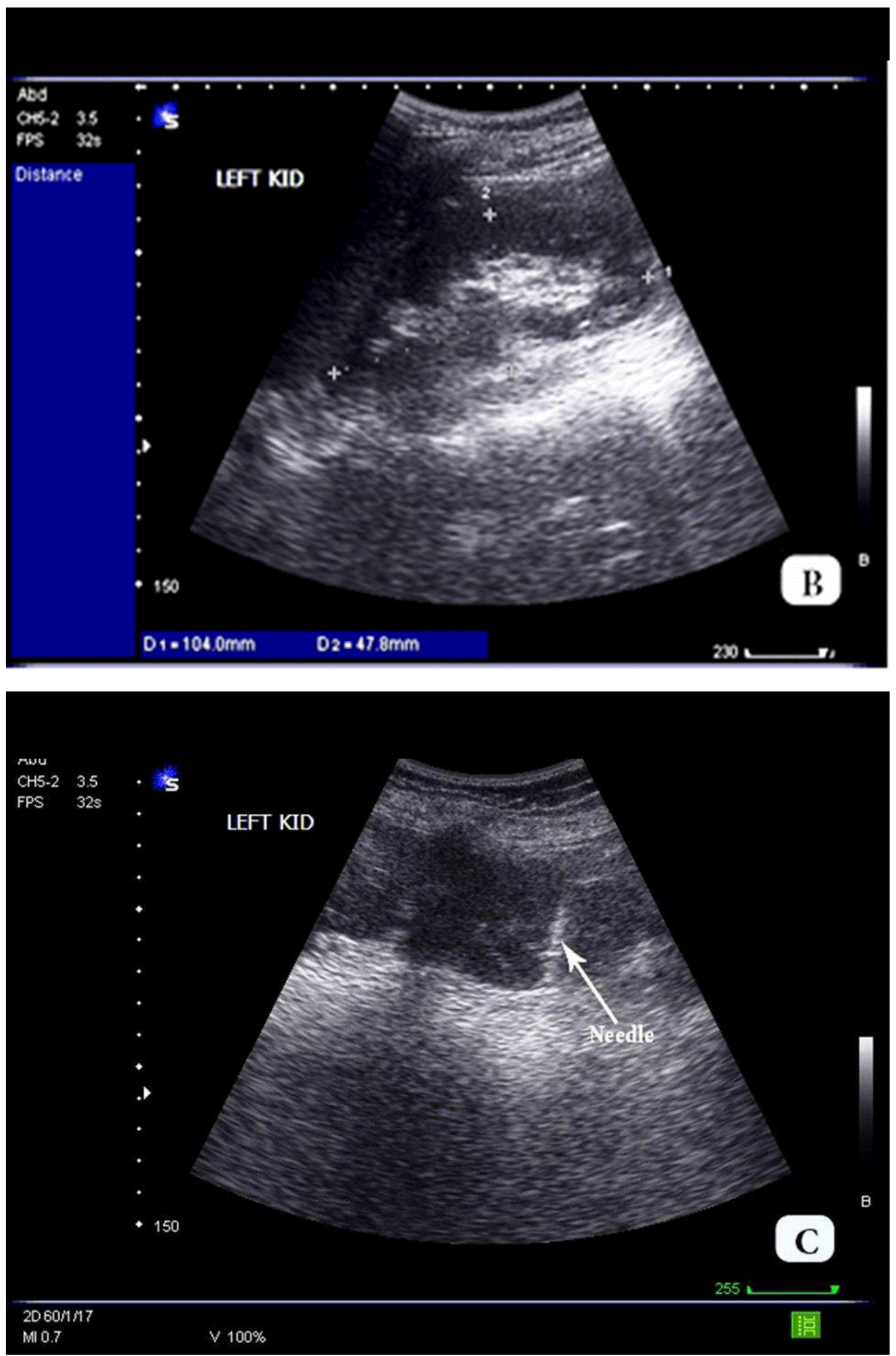

Fig. $4(4 a, 4 b \& 4 c)$. A female patient aged 23ys. (a known case of SLE with lupus nephritis under therapy, presented recently by subnephrotic proteinuria), referred for re-biopsy \& staging. A) \& B) Real-time U/S (LS) of both kidneys revealed; average sized either kidneys, with average parenchymal thickness \& normal reniform shape \& normal parenchymal echotexture \& with good corticomedullary differentiation. C) U/S. guided biopsy of the Lt. kidney, with visualized biopsy needle (arrowed) at its lower pole. Two U/S guided core biopsies were taken \& revealed lupus nephritis (LN) diffuse proliferative type WHO class IV. 

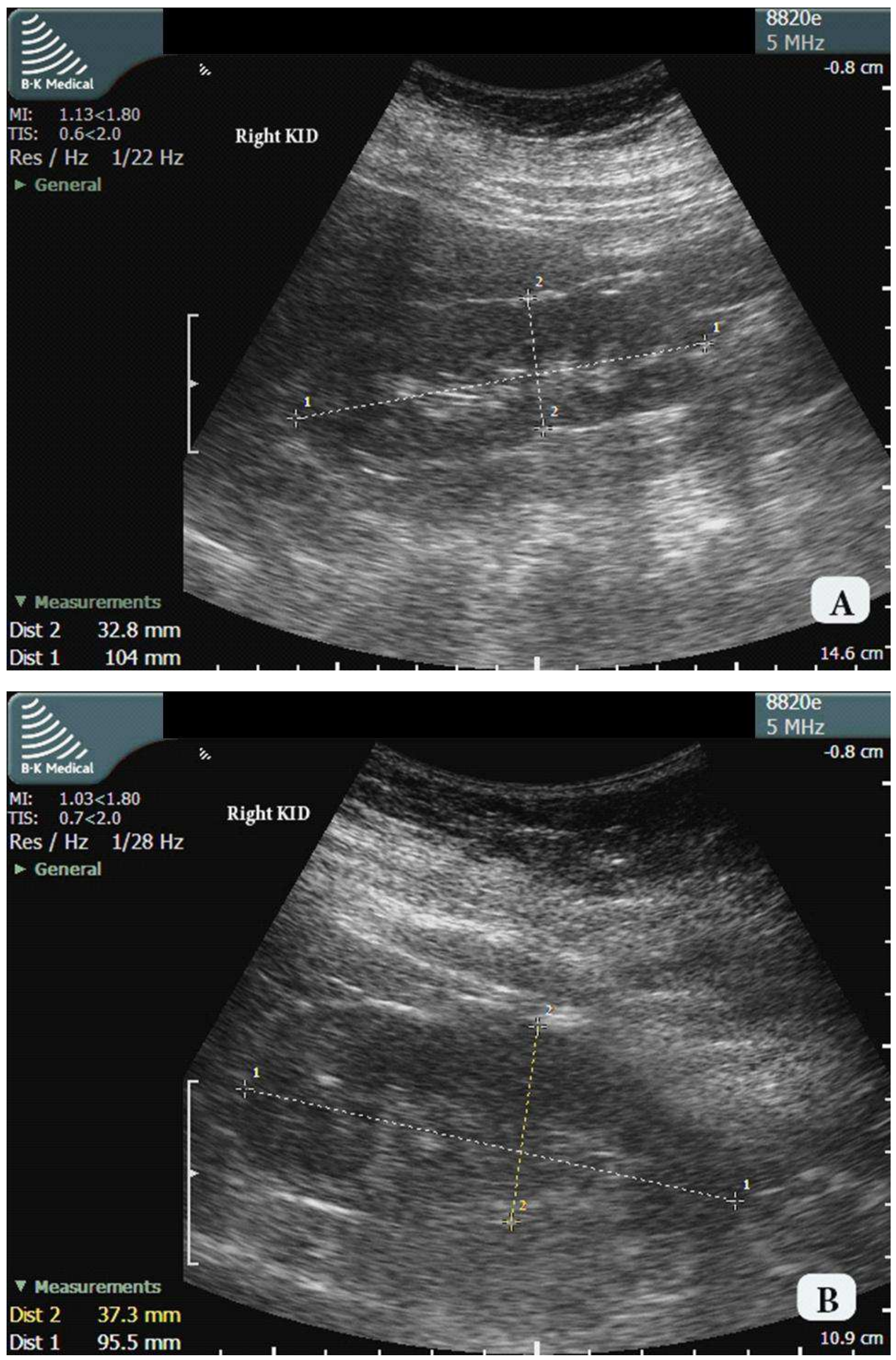


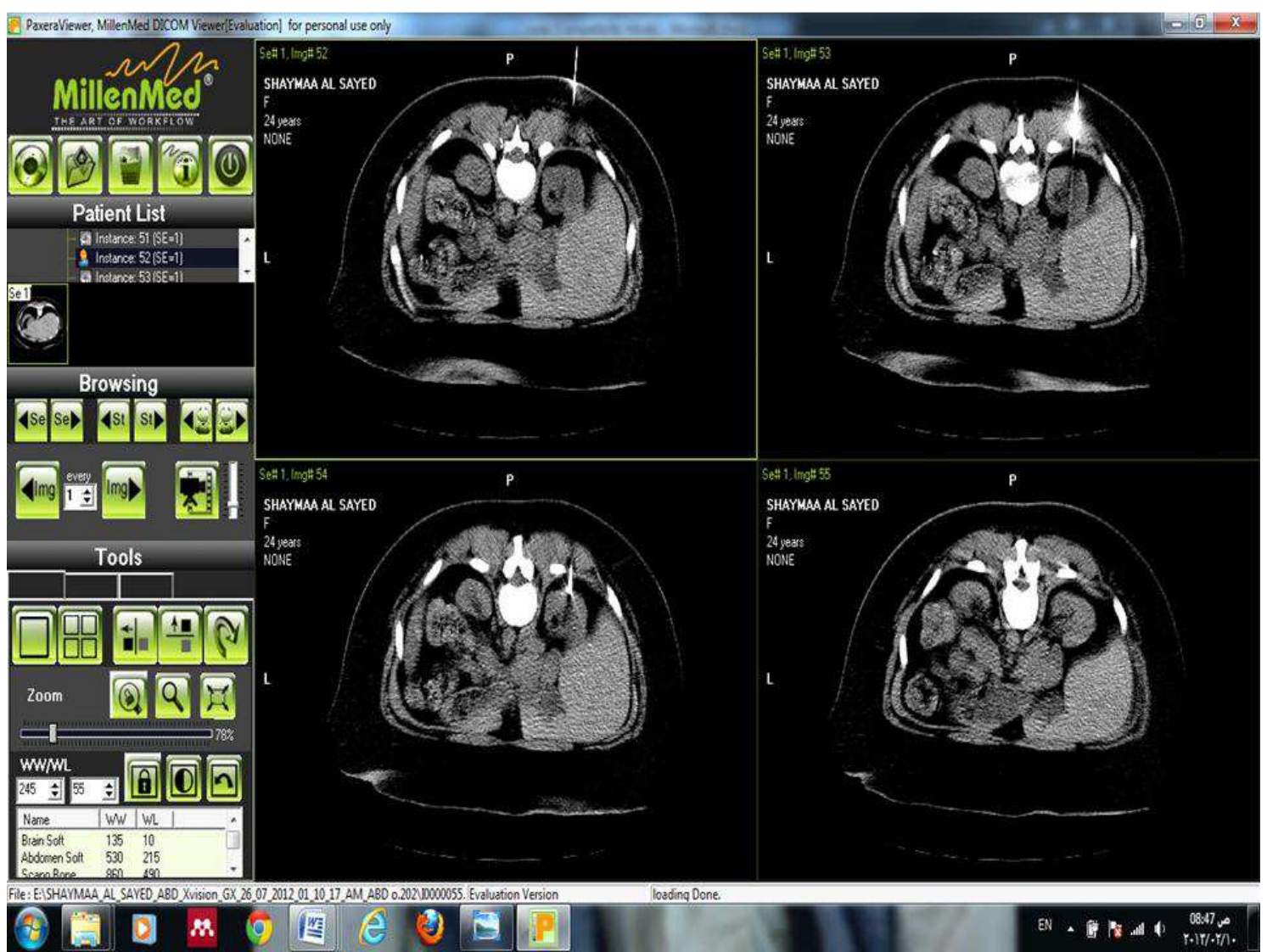

Fig. $5(\mathbf{5 a}, \mathbf{5 b}, \mathbf{8} \mathbf{5})$. A female patient aged 28ys.presented with unexplained renal impairment. (A) \& B) Real-time U/S (LS) of both kidneys revealed; an essentially average sized either kidneys with, normal reniform shape, average parenchymal thickness \& normal parenchymal echotexture except for relative increase in their parenchymal reflectivity (GI). C) Axial CT. guided biopsy of the Lt. kidney in prone position showed the tip of needle biopsy (arrowed) seen at the capsule of lower pole the Rt. kidney. Two CT guided core biopsies were taken and revealed an acute interstitial nephritis.

\section{Discussion}

Renal parenchymal disease (RPD) is defined as a disease that involves one or more compartments of the renal parenchyma (i.e. glomeruli, tubules, interstitium, or blood vessels of the kidney) [10].

The percutaneous renal biopsy (PRB) of native kidneys has been an essential tool in the diagnosis and management of renal disease for over 50 years [11]. With the evolution of imaging guidance, renal biopsy has become easier and safer [12].

Our study included 30 patients $\{22$ females(22/30) $(73.3 \%) \& 8$ males $(26.7 \%)\}$ with female to male ratio of 2.7: 1. This ratio was in accordance with that of Chan et al., 1999 (13) and Rahbar, 2009.[14] However, in other studies there was male predominance (54\%) in Barsoum and Francis, 2000 [15], (57.8\%) by Al Arrayed et al., 2004 [16], 50.6\% by Shawarby et al., 2010 [17]. This female predominence in our study was explained that the most frequent RPD was lupus nephritis (16/30) (53.3\%).

Nephrotic syndrome (NS) was the most common clinical presentation in our study (11/30) $(36.7 \%) \&$ this was nearly in agreement with that reported by Rahbar, 2009 . [14] and Ossareh et al.,2010 [18] where NS was constituting 57.4\% and $42.3 \%$ of cases respectively. NS was followed by both subnephrotic proteinuria (sub.NP) and nephritic syndrome (acute GN) as each represented by 5 cases $(16.7 \%)$. As regard to the sub.NP, higher rates were detected by Barsoum and Francis, 2000.[15] (22.4\% ) while lower rates were detected by Ossareh et al., 2010 (18)(10\%). The nephritic syndrome was near in frequency to that found by Rahbar, 2009.[14] (18\%) \& higher than that reported by Chan et al., $1999 .[13](1.2 \%)$.

Also out of 30 patients of our study 3 patients were presented by hematuria with proteinuria $(10 \%)$.This nearly was in agree with that of Tang et al (2002) .[19] (7\%) \&Torres et al (2011).[20] (12.8\%), while only 2 patients $(6.7 \%)$ were presented by hematuria, 2 patients with acute renal failure(ARF), 2 patients with chronic renal failure(CRF).

The present results showed that the most frequent RPD disease was LN (16/29) (55.2\%). This value was higher than that of other studies of Chan et al., 1999.[13], and Ossareh et al., 2010 .18] who recorded $20.5 \%, 11.6 \%$ and $11 \%$ respectively. The higher results of lupus nephritis could be attributed that most of the studied cases were known cases of SLE biopsied for the purpose of establishing a diagnosis of LN or grading and staging of already diagnosed LN and this was the main indication of renal biopsy in our study. This was followed by interstitial nephritis(IN) which accounted in three cases $(3 / 29)(10.3 \%)$, which was higher than that 
reported by Sugiyama et al., 2011 .[21] (4 \%) \& MsPGN in 2 cases $(6.9 \%)$ which coincided with that of Chan et al., $1999.113](7 \%)$ and higher than that of Ossareh et al., $2010 .[18](0.9 \%)$.

In this study adequate sample (representative) to establish the histopathological diagnosis was obtained in 29 patients (96.7\%) with average number of glomeruli (13.2 \pm 5.5$)$ and (8.9 \pm 5.8$)$ when $16 \mathrm{G}$ needle \& $18 \mathrm{G}$ needle was used respectively. The adequacy of this study was nearly similar to that reported by Garg et al., 2010.[19] (94.4\%) and Torres et al., 2011 .[20] (97.5\%) (using real-time U/S guidance and an automated biopsy device). In Garg et al., 2010 . [19] study where $18 \mathrm{G}$ needle was used, in $49 \%$ samples the yield was between 5-10 glomeruli and in $45 \%$ glomeruli were $>10$. In Torres et al., 2011.[14] study where $16 \mathrm{G}$ needle was used, in $76.9 \%$ samples the yield was $>10$ glomeruli, \&in $18.1 \%$ samples yield $6-10$ glomeruli \& in $4.8 \%$ yeild $1-5$ glomeruli.

This high percentage of effectiveness by using real time $\mathrm{U} / \mathrm{S}$ was associated with the certainty of obtaining renal tissue due to the direct vision of the kidney at the time of puncture, while in the manual technique such certainty was lacking and up to $25 \%$ of the biopsies do not have enough material for diagnosis .[20, 22]

On the other hand, within the concept of adequacy some authors considered representative biopsy, when between 8 and 10 glomeruli / sample were obtained; however, others considered representative biopsy those with which it was possible to make a histological diagnosis .[23]. There was no general consensus on the number of glomeruli needed to make the diagnosis.[24 \& 25]. However, data analysis using the number of glomeruli as a definition of efficiency may not be appropriate because as commented previously in many cases the diagnosis can be made with less than 8 glomeruli, provided histological lesions were representative for a particular disease .[24 \& 26]

In this study only two cases had post. PRB minor complications (2/30) (6.7\%) (1 with transient macrohematuria and 1 with perinepheric hematoma). This rate was similar to that reported by Tang et al., 2002.[19] (6\%), and Mishra et al., 2011.[26] (5.8\%). The high incidence of minor and major complications in some studies in comparison to our findings may be due to the fact that they used a $14 \mathrm{G}$ needle, whereas we used smaller ones. In case of major complications, the commonly required intervention was transfusion of blood products \& the need for more invasive intervention such as angiography with embolization was much less common but still occurred in up to $0.7 \%$ of biopsies, as observed even in recent reports.[26, $27 \&$ 28], while life-threatening complications resulting in death or nephrectomy were extremely rare and had not been observed in a number of recent reports .[30 \& 31]

In our study, out of 29 patients with RPD \& who had adequate PRB; 23 patients showed increase in their renal cortical echogenicity ( 13 with GI, 8 with GII, \&2 with GIII) while the remained 6 cases showed normal renal echogenicity(G0)(i.e. there was no correlation between the specific type of RPD and cortical echogenicity. A number of RPD caused increased renal cortical echogenicity but the finding was not specific to the disease, rather it reflected the degree of histopathological change within the renal parenchyma. This was consistent with findings reported by Moghazi et al., 2005.[23].

Out of 16 patients of our study who had confirmed histopathologically to be LN ; (7 cases showed GI, 5 with GII \& 4 cases with G0) \& out of 4 patients who had confirmed histopathologically to be MsPGN (2 cases showed GI, 1 with GII \& 2with G0).

Out of 29 cases of our study who had adequate PRB; 25 cases showed glomerular changes (25/29)(86.2\%)(13 with GI, 7 with GII, 2 with GIII \&3 with G0), while the remained 4 cases hadn't glomerular changes ( 3 with G0 \&1 with GII). The commonest glomerular changes were mesangial hypercellularity $(8 / 25)(32 \%)(5$ with GI, 2 with GII \& 1 with G0), followed by endocapillary changes $\{(5 / 25)(20 \%)(3$ with GI, 1with GII, 1with G0)\& MsPG changes (5/25)(3 with GII, 2 with GI).

Also we found that 21 patients out of those 29 showed tubular changes $(21 / 29)(72.4 \%)(10$ with GI, 7 with GII, 2 with GI, 2 cases with G0) \& atrophic changes were the most common tubular changes $\{(18 / 21)(85.7 \%)(10$ with mild atrophic changes)( 7 with GI, 2 with GII, 1 with G0), 6 cases with moderate atrophic changes ( 5 with GII, 1 with GI), 1 had minor atrophic changes with G0 \& the last case showed marked atrophy with GIII cortical echogenicity.

Out of 29 patients who had adequate PRB; 24 patients showed interstitial changes(24/29(82.8\%) \& the commonest interstitial changes were (fibrosis \& inflammation) $(16 / 24)(66.7 \%)(9$ with GI, 6 with GII \&1 with GI) followed by inflammation $(4 / 24)(25 \%)(2$ with GI \& 2 with GII), fibrosis $(3 / 24)(12.5 \%)(1$ with G0, 1 with GI \& 1 with GIII) \& edema $(1 / 24)(4.2 \%)$ with G0.

So in our study we found that there was no correlation between the specific type of RPD disease and cortical echogenicity, while there was correlation between the tubular and interstitial changes and cortical echogenicity because the cortex is composed of tubules and interstitial tissue. This is in agree with Rosenfield and Siegel, 1981.[33] who found a definite relation between the tubule-interstitial changes and the cortical echogenicity while there was no correlation between the glomerlular changes and the cortical echogenicity. Also, a recent study by Moghazi et al., 2005.[33] found that tubular atrophy and interstitial inflammation, but not interstitial fibrosis were significant determinants of cortical echogenicity.

\section{Conclusion}

The renal biopsy is a fundamental procedure for the diagnosis, monitoring, prognosis, and treatment of patients with RPD, where it allows clinicians to establish a histological diagnosis and utilize the information for the diagnosis \& monitoring of treatment. With the evolution of imaging guidance, renal biopsy has become easier and safer. 
Ultrasound guided PRB is the standard method for most nonfocal renal biopsies as it has the advantage of real-time needle placement and no radiation. CT guidance provides an alternative to US in cases of extreme adiposity (poor image quality) or repeated failure of US guided percutaneous biopsy, but it exposes patient to radiation, takes more time and is more costly. Ultrasound guided and CT guided PRB is generally considered safe with minimal risk \&had very high adequacy in diagnosis of RPD. The value of PRB in native \& transplanted kidney is to predict prognosis, to diagnose etiology \& expect the net results.

\section{Abbreviation}

$\mathrm{CKD}=$ Chronic kidney disease.,

$\mathrm{CRF}=$ chronic renal failure.,

$\mathrm{ESRD}=$ end stage renal disease.,

$\mathrm{GFR}=$ Glomerular filtration rate.,

$\mathrm{GN}=$ glomerulonephritis.,

HUS=hemolytic uremic syndrome.,

$\mathrm{LN}=$ lupus nephritis.,

$\mathrm{MCD}=$ minimal change disease.,

$\mathrm{MGN}=$ membranoproliferative glomerulonephritis.,

MsPGN= mesangioproliferative glomerulonephritis.,

$\mathrm{PRB}=$ percutaneous renal biopsy.,

$\mathrm{RPD}=$ renal parenchymal disease.,

$\mathrm{SLE}=$ systemic lupus erythematosus.,

TMA=Thrombotic microangiopathy.,

NHANES III=third national health and nutrition

examination survey.

US=Ultrasonography.,

$\mathrm{CT}=$ Computed tomography.,

$\mathrm{WHO}=$ world health organization.

\section{References}

[1] Stevens PE, O'Donoghue DJ, de LS et al. Chronic kidney disease management in the UnitedKingdom: NEOERICA project results. Kidney Int 2007; 72(1): 92-99.

[2] Coresh J, Astor BC, Greene T, Eknoyan G, Levey AS. Prevalence of chronic kidney disease and decreased kidney function in the adult US population: Third National Health and Nutrition Examination Survey. Am J Kidney Dis 2003; 41(1): 1-12.

[3] Barsoum RS. End-stage renal disease in North Africa. Kidney Int Suppl 2003; (83): S111-S114.

[4] Fiorini F, Barozzi L. The role of ultrasonography in the study of medical nephropathy. Journal of Ultrasound 2007; 10(4): 161-167.

[5] Buturovi-ç-Ponikvar J, Visnar-Perovic A. Ultrasonography in chronic renal failure. Eur J Radiol 2003; 46(2): 115-122.

[6] Alebiosu CO, Kadiri S. Percutaneous renal biopsy as an outpatient procedure. J Natl Med Assoc 2004; 96(9): 12151218.

[7] Salama AD. Renal biopsy. Medicine 2011; 39(6): 339-342.
[8] Uppot RN, Harisinghani MG, Gervais DA. Imaging-guided percutaneous renal biopsy: rationale and approach. AJR Am J Roentgenol 2010; 194(6): 1443-1449.

[9] Garg AK, Kanitkar M, Venkateshwar V. Clinicopathological spectrum of renal biopsies in children. Medical Journal Armed Forces India 2010; 66(3): 216-219.

[10] Riccabona M, Mache C, Ring E. Renal Parenchymal Disease. In: Fotter R, editor. Pediatric Uroradiology.Berlin, Heidelberg: Springer; 2008. 355-383

[11] Waldo B, Korbet SM, Freimanis MG, Lewis EJ. The value of post-biopsy ultrasound in predicting complications after percutaneous renal biopsy of native kidneys. Nephrology Dialysis Transplantation 2009; 24(8): 2433-2439.

[12] Atwell TD, Smith RL, Hesley GK et al. Incidence of bleeding after 15,181 percutaneous biopsies and the role of aspirin. AJR Am J Roentgenol 2010; 194(3): 784-789.

[13] Chan KW, Chan TM, Cheng IK. Clinical and pathological characteristics of patients with glomerular diseases at a university teaching hospital: 5-year prospective review. Hong Kong Med J 1999; 5(3): 240-244.

[14] Rahbar M. Kidney biopsy in west of Iran: Complications and histopathological findings. Indian J Nephrol 2009; 19(2): 68-70.

[15] Francis M, Barsoum R. Spectrum of Glomerulonephritis in Egypt. Saudi J Kidney Dis Transpl 2000; 11(3): 421-429.

[16] Al Arrayed A, George SM, Malik AK et al. The spectrum of glomerular diseases in the kingdom of bahrain: An epidemiological study based on renal biopsy interpretation. Transplantation proceedings 2004; 36(6): 1792-1795.

[17] Shawarby M, Al Tamimi D, Al Mueilo S et al. A Clinicopathologic Study of Glomerular Disease: Experience of the King Fahd Hospital of the University, Eastern Province, Saudi Arabia. Hong Kong Journal of Nephrology 2010; 12(1): 20-30.

[18] Ossareh S, Asgari M, Abdi E et al. Renal biopsy findings in Iran: case series report from a referral kidney center. Int Urol Nephrol 2010; 42(4): 1031-1040.

[19] Tang S, Li JH, Lui SL, Chan TM, Cheng IK, Lai KN. Freehand, ultrasound-guided percutaneous renal biopsy: experience from a single operator. Eur J Radiol 2002; 41(1): 65-69.

[20] Torres MA, Valdez-Ortiz R, Gonzalez-Parra C et al. Percutaneous renal biopsy of native kidneys: Effeciency, saftey, \& risk factors associated with major complications. Arch Med Sci 2011; 7 (5): 823-831.

[21] Sugiyama H, Yokoyama H, Sato H et al. Japan Renal Biopsy Registry: the first nationwide, web-based, and prospective registry system of renal biopsies in Japan. Clin Exp Nephrol 2011; 15(4): 493-503.

[22] Burstein DM, Korbet SM, Schwartz MM. The use of the automatic core biopsy system in percutaneous renal biopsies: a comparative study. Am J Kidney Dis 1993; 22(4): 545-552.

[23] Corwin HL, Schwartz MM, Lewis EJ. The importance of sample size in the interpretation of the renal biopsy. Am J Nephrol 1988; 8(2): 85-89.

[24] Castro R, Sequeira MJ, Sameiro FM et al. Percutaneous kidney biopsy: eight years-experience. Acta Med Port 2004; 17(1): 20-26. 
[25] Gonzalez-Michaca L, Chew-Wong A, Soltero L, Gamba G, Correa-Rotter R. Percutaneous kidney biopsy, analysis of 26 years: complication rate and risk factors; comment. Rev Invest Clin 2000; 52(2): 125-131.

[26] Mishra A, Tarsin R, Elhabbash B et al. Percutaneous ultrasound-guided renal biopsy. Saudi J Kidney Dis Transpl 2011; 22(4): 746-750.

[27] Whittier WL, Korbet SM. Timing of complications in percutaneous renal biopsy. J Am Soc Nephrol 2004; 15(1): 142-147.

[28] Manno C, Strippoli GF, Arnesano L et al. Predictors of bleeding complications in percutaneous ultrasound-guided renal biopsy. Kidney Int 2004; 66(4): 1570-1577.

[29] Eiro M, Katoh T, Watanabe T. Risk factors for bleeding complications in percutaneous renal biopsy. Clin Exp Nephrol 2005; 9(1): 40-45.
[30] Bach D, Wirth C, Schott G, Hollenbeck M, Grabensee B. Percutaneous renal biopsy: three years of experience with the biopty gun in 761 cases--a survey of results and complications. Int Urol Nephrol 1999; 31(1): 15-22.

[31] Simckes AM, Blowey DL, Gyves KM, Alon US. Success and safety of same-day kidney biopsy in children and adolescents. Pediatr Nephrol 2000; 14(10-11): 946-952.

[32] Moghazi S, Jones E, Schroepple J et al. Correlation of renal histopathology with sonographic findings. Kidney Int 2005; 67(4): 1515-1520.

[33] Rosenfield AT, Siegel NJ. Renal parenchymal disease: histopathologic-sonographic correlation. American Journal of Roentgenology 1981; 137(4): 793-798. 